\title{
Epicardial and Intramural Excitation of Normal Heart in Six Patients 50 Years of Age and Older
}

\author{
J. P. ROOS, R.TH.VAN DAM, AND D. DURRER \\ From the University Department of Cardiology and Clinical Physiology, Wilhelmina Gasthuis, Amsterdam; \\ and the University Department of Cardiology, Academisch Ziekenhuis, Leiden, The Netherlands
}

Our knowledge of the pathway of excitation in the human heart is restricted mainly to the time sequence of subepicardial muscle depolarization, but even this aspect of cardiac excitation is known insufficiently, despite a large number of investigations. In many of these studies direct-writing apparatuses of low frequency response are used; these give rise to deformation of the $\mathrm{QRS}$ complexes, difficulties in recognition of the intrinsic deflections, and therefore inaccuracies in the measurement of the time of occurrence.

In some studies a string galvanometer with its better physical properties has been used as a recording instrument. Groedel and Borchardt (1948) recorded cardiac potentials by placing small electrodes on the pericardial surface during artificial pneumothorax. The localization of the exploring electrode during this procedure is difficult, and it is not possible to explore a sufficient number of points. In the classic study of Barker, Macleod, and Alexander (1930), 15 regions located at the anterior and posterior epicardial surfaces of an exposed human heart were explored. Their results, so far as the excitation pattern during normal beats is concerned, will be discussed later. A highfidelity recording machine and fast running film were used by Jouve et al. (1958, 1960). Highly detailed complexes from many parts of the epicardial surface of the human heart were recorded.

In our study, a similar technique was used. Epicardial exploration was combined with the introduction into the left ventricular wall of one intramural electrode in each patient, in whom the left ventricular surface was explored. The normal hearts were those of 6 patients between 50 and 68 years of age, undergoing pneumonectomy for pul-

Received December 6, 1967. monary neoplasm. These hearts were not enlarged and the electrocardiograms were within normal limits.

\section{Patients and Methods}

Epicardial excitation was studied by unipolar leads taken by means of a small-tipped platinum electrode, with a surface smaller than 1 sq.mm. The peripheral electrode was Wilson's "central terminal". In 3 of the 6 patients, the anterior surface of the right ventricle and the adjacent part of the left ventricle were explored; in the other 3 patients the anterior and posterior surfaces of the left ventricle and adjacent parts of the right ventricle were studied; in one patient both ventricles were explored. The number of epicardial points in the individual patients varied, as can be seen in Fig. 1. An oscillograph (frequency response up to 3200 c.p.s. time for these records $0.1 \mathrm{sec}$.) with separate recording and viewing tubes was used for the registration; the 'vertical movements of the spot on the screen were photographed on a film, moving at a constant speed of $6.4 \mathrm{~cm}$. $/ \mathrm{sec}$. The distance between the time marks was $300 \mathrm{msec}$. For the measurement of time relations of excitation, the rapid part of the intrinsic deflection in unipolar and bipolar complexes was used (Durrer, van der Tweel, and Blickman, 1954). In all cases the beginning of the left ventricular cavity complex was used as a time reference. After pericardiotomy, a careful drawing of the exposed surface of the heart was made. The position of the electrodes was marked on this drawing. The form of the recorded complexes and their time relations were studied. The complexes were enlarged three times, and no retouching was done. The enlarged complexes were placed on those regions of the drawing of the heart from which they were recorded during operation. This composite picture was photographed for the final illustration. In some patients one intramural electrode, described previously (Durrer, 1952; Durrer and van der Tweel, 1953), could be introduced into the left ventricular wall. Bipolar complexes were recorded between consecutive intramural terminals 
$\underline{A}$
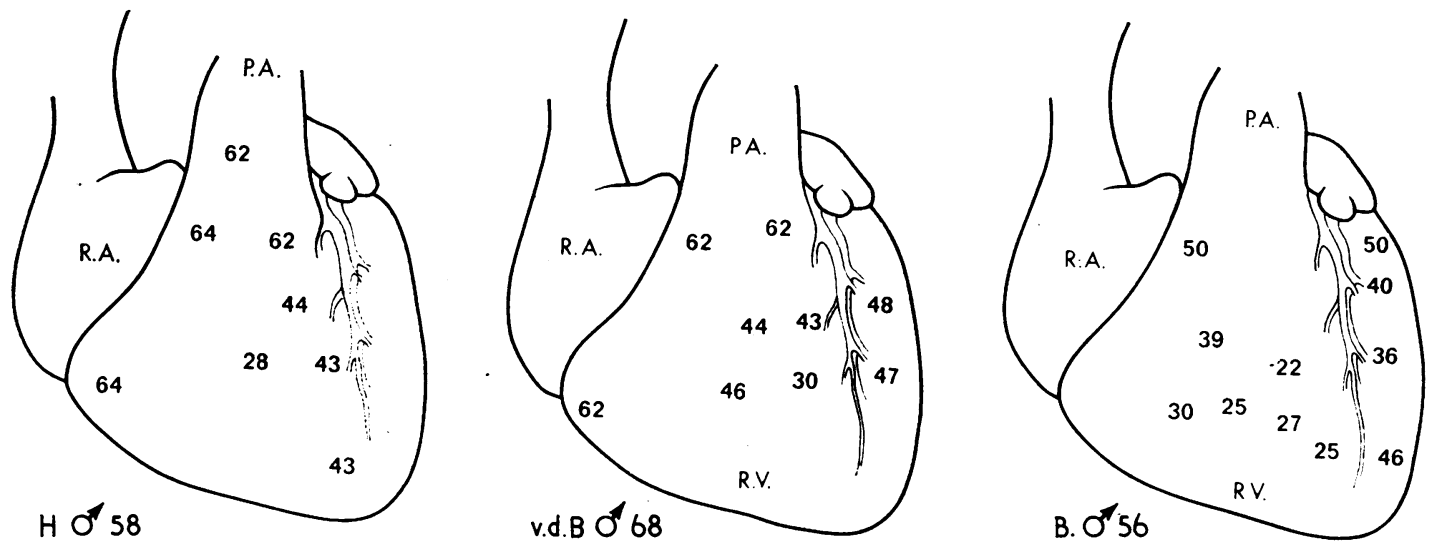

$\underline{B}$
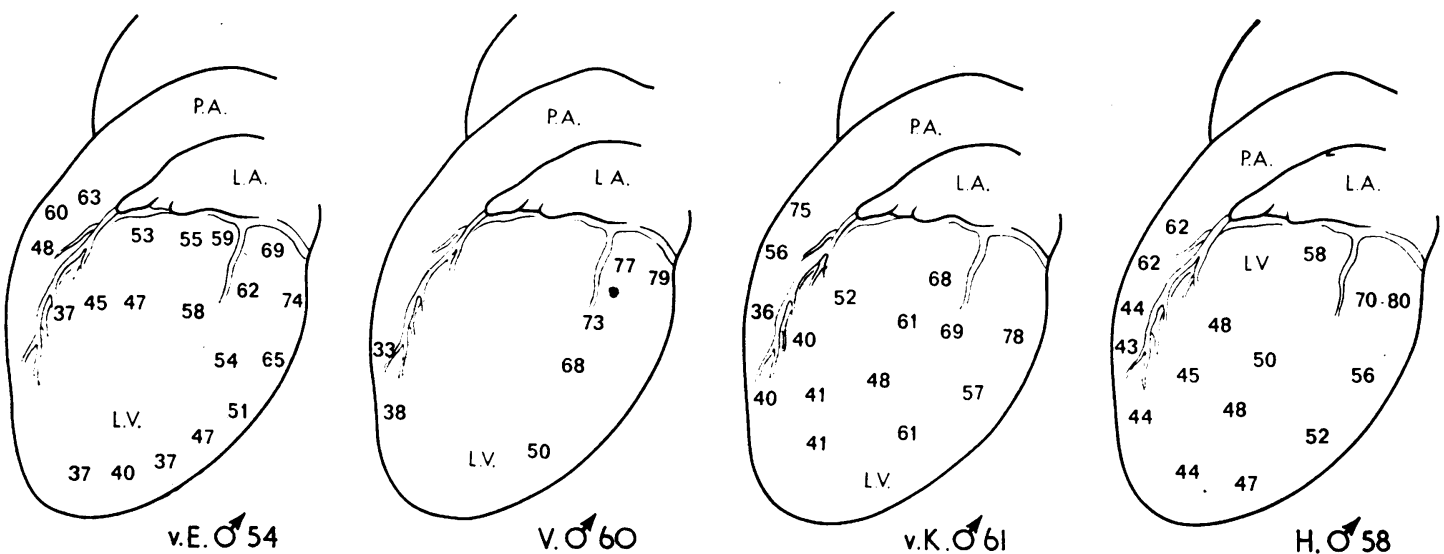

FIG. $1 \mathrm{~A}$ and B.-Schematic epicardial surface maps of the right (A) and left (B) ventricles in the 6 patients explored.

Figures indicate local excitation times in msec. following the onset of the left ventricular cavity complex.

of this intramural electrode; the polarity of the bipolar complexes was positive, if outward spread of the excitatory wave was present.

\section{RESULTS}

A: Time Relations of Epicardial Excitation (Fig. 1 and 2). The results of epicardial excitation studies in the individual patients are depicted in Fig. $1 \mathrm{~A}$ and $B$. It is evident that the variations in excitation time in corresponding regions are relatively small and that there exists an over-all pattern in the sequence of epicardial excitation; this is summarized in Fig. $2 \mathrm{~A}$ and $\mathrm{B}$. The right anteroparaseptal region (area trabecularis) is the first epicardial region to be activated. Here epicardial breakthrough occurs about $20 \mathrm{msec}$. after the begin- ning of ventricular depolarization and is followed by a spread across the epicardial surface in a more or less radial direction. In the right ventricle the conus pulmonalis is the area last activated (60$70 \mathrm{msec}$.). The area of the right ventricle near the right atrium is also activated late $(50-60 \mathrm{msec}$.). Over the left ventricle, the epicardial excitation spreads from the anterior paraseptal area (30-40 msec.) to the lateral border $(60-70 \mathrm{msec}$.$) . The$ postero-basal area of the left ventricle is the last activated region (70-80 $\mathrm{msec}$.).

B: Shape of Epicardial Complexes (Fig. 3 and 4). The main deflections of the epicardial complexes from corresponding regions of the hearts do not differ appreciably, but great variations of minor 


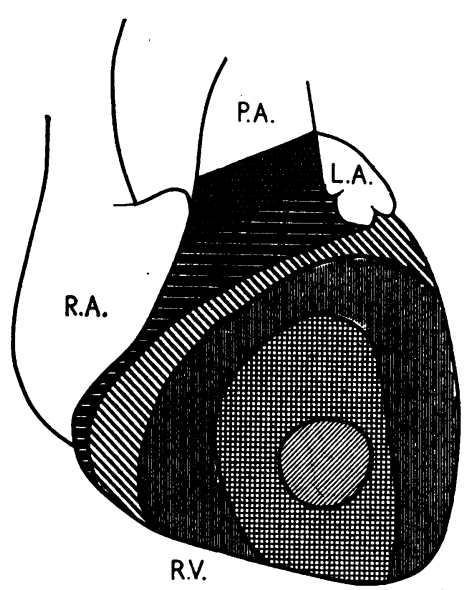

A
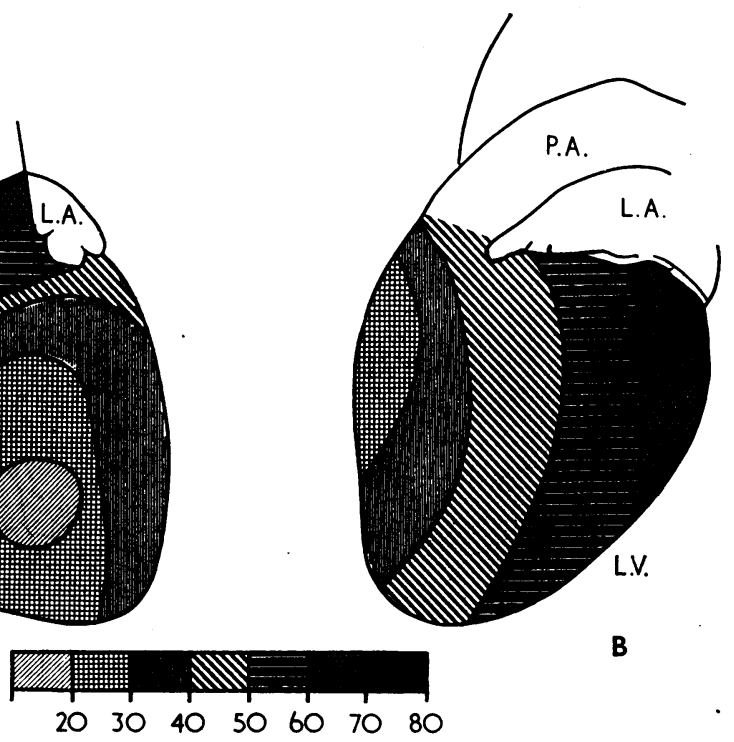

B

msec.

FIG. $2 \mathrm{~A}$ and B.-Schematic representation of epicardial activation of the human heart, which summarizes the results obtained in the 6 hearts explored. (A) Anterior surface of the heart; (B) lateral surface of the heart.

The areas indicated are activated within $10 \mathrm{msec}$. intervals. The earliest activated area is the area trabecularis. The postero-basal region is activated latest in the cardiac cycle.

details, as presence and degree of notches and slurring, can be seen. These major deflections may be described as follows.

(i) Right ventricular surface (Fig. 3). Complexes with an $\mathrm{rS}$ form are present in the earliest activated. part of the right ventricle in all cases. The voltage of the $r$ wave varies from $3-5 \mathrm{mV}$, while the $S$ wave shows a voltage of $8-20 \mathrm{mV}$. The beginning and the first part of the $r$ wave of the epicardial complex in this area coincides with the $r$ wave of the right ventricular cavity complex, which has a duration of $25 \mathrm{msec}$., while the top occurs $15 \mathrm{msec}$. after its beginning. The intrinsic deflections of the epicardial complexes in this area have a duration of 2-4 msec., and a voltage varying from 5-10 mV. Sometimes one or two notches are visible. The nadir of the $S$ wave $(40 \mathrm{msec}$. after reference) coincides with the nadir of the right ventricular cavity complex.

In the region activated later, a slight increase in duration and in height of the $r$ wave is visible. Secondary $\mathbf{R}$ waves, often deeply notched, are present at the outflow tract region of the right ventricle. In these complexes, too, the nadir of the first $S$ wave is synchronous with the nadir of the right ventricular cavity complex. (ii) Anterior attachment of interventricular septum (Fig. $4 A$ and $B$ ). There is a striking correspondence in form of the complexes overlying and at both sides of the anterior attachment of the interventricular septum (Fig. 4). They have an $\mathrm{rS}$ form. At the left side of this region no q waves are present; in this left ventricular region complexes with an isoelectric part, preceding the $r$ wave and lasting about 5-10 msec., are sometimes found. Broadtipped positive waves of low voltage $(1-2 \mathrm{mV})$ and a duration of about $20 \mathrm{msec}$. are visible in a small area, located mainly in the apical third part of the region overlying the anterior attachment of the interventricular septum. The beginning of this wave coincides with the beginning of the right or left ventricular cavity complex. These are the $\mathrm{v}$ waves as described by Jouve et al. $(1958,1960)$.

(iii) Left ventricular surface (Fig. $4 A$ and $B$ ). In the complexes derived from the antero-lateral, lateral, and posterior sides of the left ventricle, $q$ waves without any notching are recorded. In the anterior and antero-lateral region this wave has a maximal duration of $30 \mathrm{msec}$. The duration of the q waves is maximal in the postero-basal area ( 35 msec.), while the voltage varies between $\frac{1}{2}-3 \mathrm{mV}$. The beginning of the $q$ waves is always synchronous with the beginning of the left ventricular cavity 
complex. At a greater distance from the anterior attachment of the ventricular septum, the $R$ wave increases in size; on the lateral border the $R$ wave has a height of about $20 \mathrm{mV}$. The duration of the intrinsic deflections, which do not show notching, is 1-2 msec. The top of the $R$ wave is often somewhat rounded and slightly notched. The height of the $R$ wave may differ very significantly in closely adjacent epicardial regions.

Deep $S$ waves are present at the anterior side of the left ventricle from apex to base. In lateral direction the $S$ wave diminishes in size, but even in the postero-basal area a small $S$ wave is always present.

C: Intramural Excitation (Fig. $5 \mathrm{~A}$ and $\mathrm{B}$ ). The circumstances during surgery dictated the location of the region where the intramural electrode could be introduced into the left ventricular wall. In nearly all cases the intramural electrode was put into the antero-lateral region of the left ventricle, half-way between apex and basis. The unipolar complexes from the consecutive intramural terminals show a gradual transition from the complex recorded in the cavity or subendocardial muscle

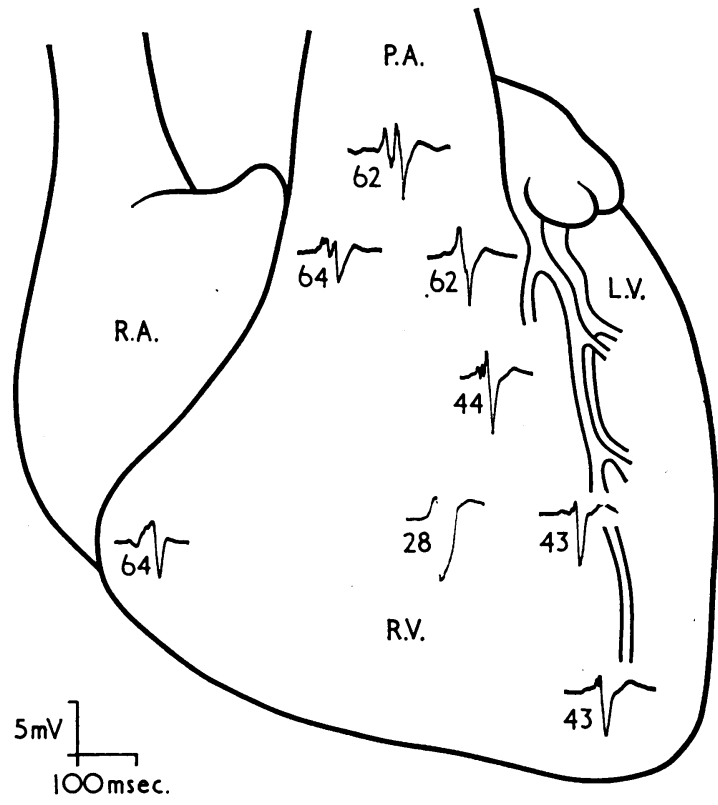

Fig. 3.-Unipolar epicardial complexes of the right ventricle.
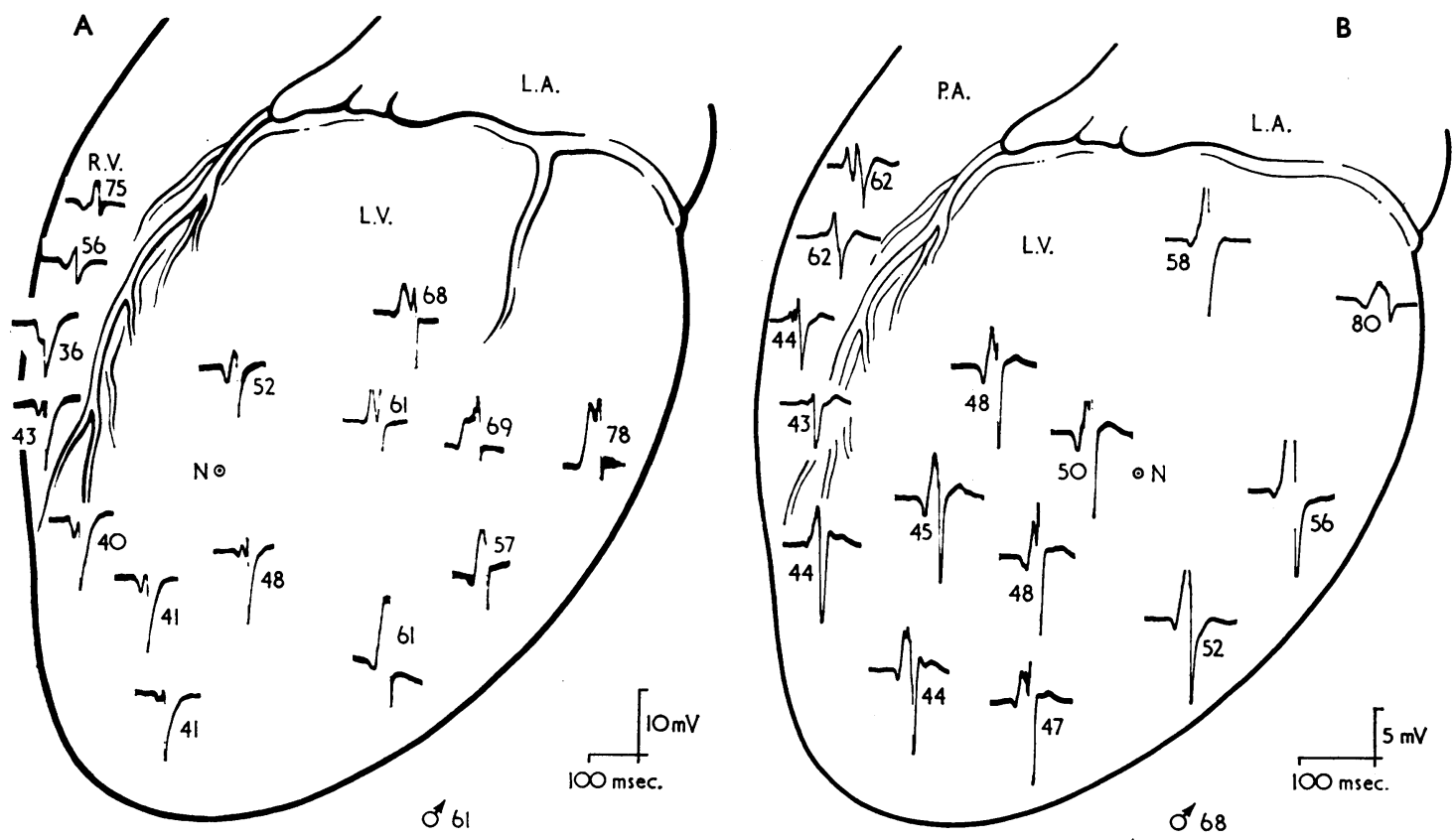

Fig. $4 \mathrm{~A}$ and B.-Epicardial complexes of the anterior and lateral part of the left ventricle of the heart. The figures indicate the time of arrival of the excitatory wave.

(A) The scalar and praecordial electrocardiogram in this case was within normal limits. (B) In this patient the mean QRS axis was $-15^{\circ}$.

No differences in epicardial excitation time of the regions shown are present. 

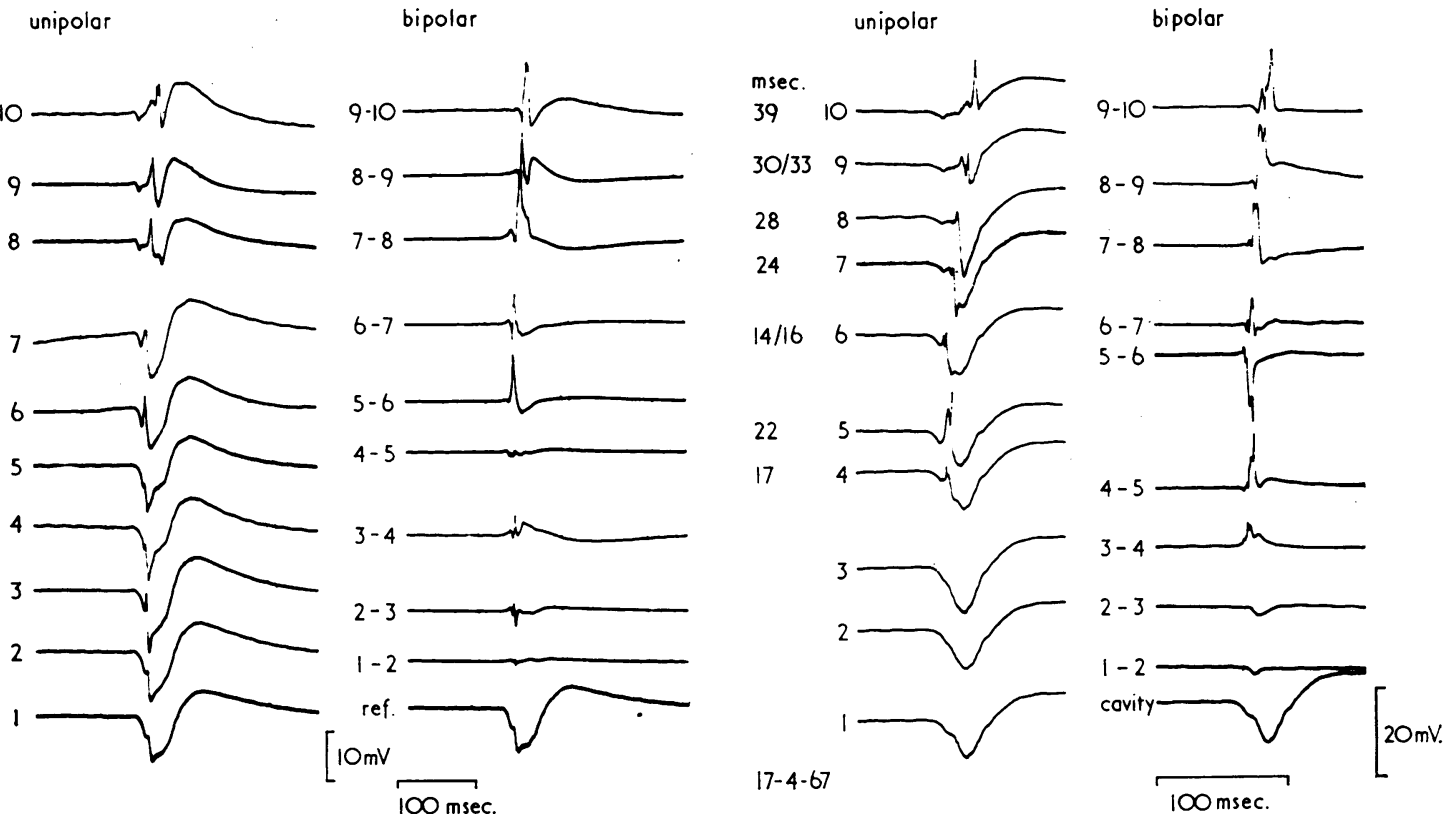

A

FIG. $5 \mathrm{~A}$ and B.-Unipolar and bipolar intramural complexes from the lateral surface of the left ventricle. Regular outward spread is present in the outer layers.

(A) There is a gradual increase in size of the $\mathbf{R}$ wave in the unipolar complexes towards the epicardial surface. (B) The figures in the complexes indicate the time of arrival of the excitatory wave.

layer to the epicardial complex. The greatest increase in $\mathbf{R}$ wave often occurs in the outer layers of the ventricular wall.

The bipolar complexes between consecutive terminals were all positive in the middle and outer layers of the ventricular wall. They are smooth, but in some patients slight notching is present. The voltage is $10-20 \mathrm{mV}$. In the inner layers smaller, sometimes notched, bipolar complexes were recorded. Complexes that were predominantly negative were rarely seen (Fig. $5 \mathrm{~B}$, bipolar complex 5-6). In one patient a rapid deflection with a duration of 2 msec. and a voltage of about $5 \mathrm{mV}$, occurring $10 \mathrm{msec}$. after the beginning of the reference, precedes the intramural bipolar complex recorded between 2 terminals situated in the inner layer of the ventricular wall and the intramural complex recorded from one of these terminals. The shape of this deflection and the time of occurrence make it probable that it was due to Purkinje activity (Fig. 6).

\section{Discussion}

Because of the presence of ventricular hypertrophy in patients with acquired or congenital heart disease, data about epicardial excitation of normal hearts could only be obtained during lung operation for pulmonary disease, that is in the older age-group. This makes it likely that coronary heart disease is present, even in view of the fact that no clinical data or electrocardiographic arguments were found to substantiate this suspicion. The great degree of correspondence of the results compared with those obtained from non-hypertrophic ventricles in operations on patients with heart disease of all age-groups (Durrer, Roos, and Büller, 1965) supports the conclusion that the degree of coronary heart disease present does not invalidate the conclusions.

The beginning of left ventricular cavity complex was used as a time reference. It has been demonstrated that in the human heart, as in the dog heart, the beginning of the cavity complex coincides more closely with the onset of ventricular depolarization than the beginning of a peripheral lead (Durrer, Roos, and van Dam, 1966). The cavity complex is also useful for the analysis of the form of the complexes recorded from its epicardial surface.

Epicardial Excitation. While the numbers of epicardial points explored are insufficient to describe the epicardial excitation pattern in all details, it is evident that the distribution of the isochrones, 


\section{Epicardial and Intramural Excitation of Heart in Six Patients}

which was very similar in all hearts explored, indicates the presence of a double envelopment of the surface of both ventricles, starting at the area trabecularis, with the postero-basal region activated latest. This does not imply that this is the latest activated region of the heart as well. The presence of a smaller or larger $S$ wave in the posterobasal complexes indicates that after excitation of this region ventricular activation is not completed. Probably excitation is still present in basal parts of the ventricular septum. This excitation pattern, also found in hearts with congenital or acquired heart disease (Durrer et al., 1965), which resembles that present in the dog heart, differs profoundly from the results obtained by Barker et al. (1930) in their study of an exposed human heart. In this heart with purulent pericarditis they used the beginning of $R$ in lead II as zero point. Earliest excitation occurred at the anterior side of the right ventricle $(10 \mathrm{msec}$.$) , but at a much higher region$ than in our study. Other right ventricular regions that were activated slightly later were the outflow tract region $(14 \mathrm{msec}$.) and near the base of the papillary muscle (15 msec.). The left ventricular surface also showed earliest activation in the high antero-lateral region $(16 \mathrm{msec}$.$) . The latest part$ of this surface to be activated was the posterobasal region ( $30 \mathrm{msec}$.). The time intervals we found are much larger. This may be caused by the different reference complex used. We sometimes found time differences of $20-25 \mathrm{msec}$. between the beginning of lead II and the cavity complex. Moreover, the influence of respiration on the latter complex can be discarded, but not on the beginning of lead II.

\section{Shape of Epicardial Complexes}

(A). Right ventricular surface. The intrinsic deflections in the right ventricular epicardial complexes have a much smaller voltage than those recorded from the left ventricle, and are of slightly longer duration, 2-4 msec. versus 1-2 $\mathrm{msec}$. This may be caused by a smaller voltage of the intramural equivalent dipole layer in the normal right ventricular wall, because of its thinness and a reduced conduction velocity. No intramural electrodes were introduced into the right ventricular wall. Thus, no data about the strength of the right ventricular intramural equivalent dipole layer and conduction velocity of intramural excitation are available. The slight differences in form between the right ventricular cavity complex and the epicardial complexes, recorded from the central region of the free wall of the right ventricle, support the contention that the thin right ventricular muscle layer does 4
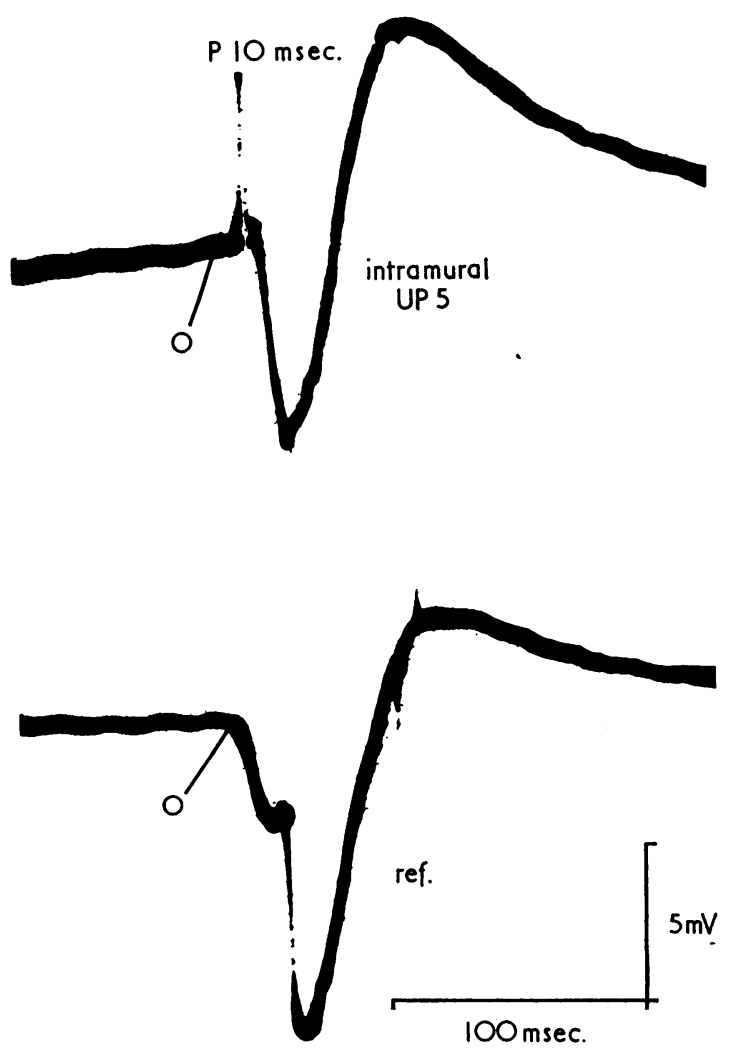

Fig. 6.-Top: The unipolar complex recorded from terminal 5 of an intramural electrode, showing a rapid deflection probably due to Purkinje activity.

Bottom: Unipolar reference lead from the left ventricular cavity.

not contribute significantly to the form of the epicardial complexes recorded from this region.

The extent to which the right ventricular wall is supplied by a subendocardial Purkinje network could not be ascertained. The relatively large right ventricular area, activated in the first 30 msec. of ventricular excitation, indicates the presence of a subendocardial Purkinje network in that region. The smaller distance between the isochrones in the basal region of the right ventricle suggests absence or scarcity of subendocardial Purkinje excitation. It may be expected that here the direction of propagation of the intramural excitation wave will be oriented in a more tangential direction.

While fully aware of the influence of excitation of the crista supraventricularis on the presence of late and secondary $R$ waves in the outflow tract region, we want to point out that tangential excitation, at a late moment of the outflow tract of the 
right ventricle, might be a contributing factor of some significance. The notching of the secondary $\mathrm{R}$ waves in the pulmonary conus region may be caused by local factors, as large differences in spatial orientation of muscle bundles in this small region, and by the presence during the end phase of ventricular depolarization of several excitatory waves, progressing in different directions, in closely adjacent parts of the heart, as the ventricular septum, the crista supraventricularis, and the free wall of the right ventricular outflow tract.

(B). Anterior attachment of ventricular septum. We assume that the small, smooth, broad-tipped positive $\mathrm{v}$ waves occurring at the very beginning of ventricular depolarization, recorded from the epicardial surface overlying the anterior attachment of the interventricular septum, are due to septal excitatory forces, occurring in the first 5-10 msec. and progressing in an anterior direction. The results obtained in a study of the total excitation of an isolated normal human heart support this hypothesis.

The $R$ waves in this region are very small, the $S$ wave is deep. They resemble right ventricular complexes recorded from the earliest activated region. No explanation for the small voltage of the $R$ wave can be given at the moment, because no intramural electrodes were introduced into this region.

In the transitional zone between the regions showing $\mathrm{v}$ waves and $\mathrm{q}$ waves, respectively, the latter situated closer to the lateral border of the left ventricle, isoelectric parts preceding the main QRS deflection were found. It is possible that this is due to cancellation of the $v$ and $q$ waves.

(C). Left ventricular surface. At all places $Q$ waves are present, increasing in size towards the postero-basal region. In the latter region the subendocardial activation occurs late, as was found in the isolated human heart preparation and from an intramural electrode introduced into this region in one patient.

The cause of the slight notching or even bifidity of the $\mathrm{R}$ wave could not be ascertained. Several anatomical and physiological factors may be responsible: differences in thickness of closely adjacent parts of the ventricular wall, the presence at the inner surface of the papillary muscle and of deep trabeculations, and differences in depth of intramural Purkinje penetration. The notches may even be caused by small scars in the ventricular wall, giving rise to irregularities of the outward spread of the excitatory wave.
Intramural Excitation of Left Ventricle. The results obtained from the intramural electrodes support the hypothesis that intramural excitation in the left ventricular wall proceeds in a predominantly endo-epicardial direction, as occurs in the dog heart (Scher et al., 1953). Durrer and van der Tweel (1957) found in the dog heart that mainly in the apical half of the left ventricle reversal phenomena could be found, which they attributed to the presence of intramural Purkinje penetration in the inner one-third of that part of the ventricular wall. Due to the penetration of a small branch of the Purkinje system for some distance into the left ventricular wall, excitation in a small layer (about $2 \mathrm{~mm}$.) spreads in an epicardial-endocardial (inward) direction. Only in one instance (Fig. 5 B) did the bipolar complexes in the human heart resemble those found in the dog heart (Durrer et al., 1965). These results indicate that Purkinje penetration into the human left ventricular wall is not present as regularly as in the dog heart.

Conduction velocity of the intramural excitatory wave can only be measured accurately if propagation of this wave occurs parallel with the exploring electrode. This is probably not true under the conditions prevailing in the human heart, and therefore the value we find may be too high. In outer layers the time interval between consecutive terminals is $6 \mathrm{msec}$., while the distance between two electrodes is $2 \mathrm{~mm}$. So the conduction velocity through the wall is maximally about $30 \mathrm{~cm}$./ $/ \mathrm{sec}$. Purkinje activation could be recorded at the anterior side of the left ventricle. The form of the deflections is the same as in the dog.

\section{ConcLusion}

The epicardial and intramural excitation of the exposed normal human heart was studied during surgery for pulmonary disease. Excitation of the subepicardial muscle occurs first in a small portion of the right antero-paraseptal region, about 20 msec. after the beginning of ventricular depolarization. The area of the right ventricle near the right anterior atrioventricular sulcus is activated at 50$60 \mathrm{msec}$. Excitation reaches the pulmonary conus after $60-70 \mathrm{msec}$. Over the left ventricle the epicardial excitation spreads from the septal area (30$40 \mathrm{msec}$.) to the lateral border $(60-70 \mathrm{msec}$.). The postero-basal area of the left ventricle was the last activated region of the whole heart $(70-80$ msec.).

Intramural excitation in the left ventricular wall proceeds in a predominantly endo-epicardial direction. Conduction velocity is about $30 \mathrm{~cm}$. $/ \mathrm{sec}$. 
Our sincere thanks are due to Professor Dr. A. G. Brom and Professor Dr. N.G. Meijne for their cooperation, which made this study possible.

\section{REFERENCES}

Barker, P. S., Macleod, A. G., and Alexander, J. (1930). The excitatory process observed in the exposed human heart. Amer. Heart F., 5, 720.

Durrer, D. (1952). Experimenteel onderzoek naar het verloop van het activatie-proces in de hartspier. Thesis, Amsterdam.

$\longrightarrow$, Roos, J. P., and Büller, J. (1965). The spread of excitation in canine and human heart. In International Symposium on the Electrophysiology of the Heart, Milan, pp. 203-214. Ed. by B. Taccardi and G. Marchetti. Pergamon Press, Oxford.

,-- , and van Dam, R.Th. (1966). The genesis of the electrocardiogram of patients with ostium primum defects (ventral atrial septal defects). Amer. Heart f., 71, 642 .
- and van der Tweel, L. H. (1953). Spread of activation in the left ventricular wall of the dog. I. Amer. Heart $\mathcal{F}$., 46, 683.

- , and - (1957). Excitation of the left ventricular wall of the dog and goat. Ann. N.Y. Acad. Sci., 65, 779.

$\longrightarrow,-$, and Blickman, J. R. (1954). Spread of activation in the left ventricular wall of the dog. III. Amer. Heart F., 48, 13.

Groedel, F. M., and Borchardt, P. R. (1948). Direct Electrocardiography of the Human Heart and Intrathoracic Electrocardiography. Brooklyn Medical Press, New York.

Jouve, A., Corriol, J., Torresani, J., Benyamine, R., Velasque, P., and Peytavy, R. (1960). Epicardial leads in man. Amer. Heart F., 59, 856.

,-- , Velasque, P., Benyamine, R., and Peytavy, R. (1958). Les dérivations épicardiaques ventriculaires chez l'homme. Acta. cardiol. (Brux.), 13, 247.

Scher, A. M., Young, A. C., Malmgren, A. L., and Paton, R. R. (1953). Spread of electrical activity through the wall of the ventricle. Circulat. Res., 1, 539. 